\title{
Investigation of Photo-Absorption and Current-Voltage Properties of Liquid Extracts from Fruits for Organic Solar Cells Application
}

\author{
Dashty A. Babakr, Hamad H. Bayiz, Hawkar M. Qadr and Fahmi F. Muhammad \\ Soft Materials and Devices Laboratory, Department of Physics, Faculty of Science and Health, Koya \\ University, Koya, Kurdistan Region, Iraq
}

\begin{abstract}
In this research work, the optical absorption and photo-current characteristics of black grape, strawberry and orange solutions were investigated. The solutions were extracted from fresh fruits and UV-V is spectrophotometer was utilized to record the absorption spectra of the samples. Besides, the photo-current properties were investigated via current-voltage characteristics of the fruit solutions under illumination. The results showed that energy gaps of the fruits are located within the visible spectrum. Energy gap of $1.84 \mathrm{eV}$ was found for the black grape, $2.11 \mathrm{eV}$ for strawberry and $3.10 \mathrm{eV}$ for the orange solution. The broad absorption spectra for black grape and strawberry have proved the fruits capability to harvest solar energy. Additionally, the enhanced photo-current activity of the fruit solutions under light suggested their potential application for the organic and/or dyes solar cells
\end{abstract}

Keywords: Absorption, energy gap, black grape, strawberry, orange, dyes solar cells.

\section{INTRODUCTION}

Nanostructured organic solar cells (OSCs) [1, 2] and dye based solar cells [3] are important devices used to convert the sunlight directly into electricity. These devices have now received a very considerable attention due to their easy fabrication process, light weight and minimal material usage. The vast majority of researches in the field of organic solar cells are importantly focused on the optical absorption response of the active materials [4-6] used in the fabrication process. The optical absorption of the active material plays an essential role in defining the overall performance of the device [1], there by harvesting sufficient amount of solar energy to generate electricity. When light strikes a material several optical phenomena will take place; scattering, reflection, absorption, refraction, and transmission [7]. The light absorption is primarily related to the chemical constituents of the materials, whereas light scattering is influenced by structural/physical characteristics e.g. density, particle size, and cellular structures. One important criterion for materials to serve as active ingredient in the solar cell devices is that the energy gap $\left(E_{g}\right)$ of the material is located within the energy of visible light spectrum. In a research study, the optical properties of apple skin was investigated in the wavelength range from 350 to $2200 \mathrm{~nm}$ [8]. Moreover, the response of absorption coefficient spectra governed by the pigments contents (e.g. chlorophylls and carotenoids) has been utilized as a tool to estimate the ripening stages of some fruits and

*Address correspondence to this author at the Soft Materials and Devices Laboratory, Department of Physics, Faculty of Science and Health, Koya University, Koya, Kurdistan Region, Iraq; Tel: +96 4770193 5331;

E-mail: fahmi982@gmail.com, fahmi.fariq@koyauniversity.org vegetables $[9,10]$. Nassif et al. studied light scattering through fruits during ripening aiming at monitoring fruits maturation [11]. More research works on optical properties of organic materials like trunk of trees [12], fruits [13, 14], and foods [15] have been also carried out. Extensive literature showed that previous research works have been limited within the investigation of fruits for the agricultural and quality control related issues. Little attention has been paid to study the optical absorption behaviors of fruits in terms of harvesting visible light energy for the application of organic solar cells, while that organic and natural dyes are under interesting investigation for their application in photovoltaic devices [16, 17]. Therefore, the current research work was devoted to investigate the optical absorption and photocurrent (current-voltage) response of fruit extracts, namely from black grape, strawberry, and orange. It was noticed that the optical absorption of the extracted dyes are within the interesting range of solar spectrum and the photoelectric properties showed considerable deviation upon the illumination of the materials, making them a viable candidate for the application of organic solar cells and/or dye based solar cells.

\section{MATERIALS AND METHODS}

The fruits; strawberry, orange, and black grape were collected in fresh form and they were cleaned thoroughly to be ready for extracting their juices. The liquid extraction (juice solution) was performed by cutting and pressing process of the fruits. Then, filtration paper (20 $\mu \mathrm{m}$ pore size) was used to refine the extracts and to produce a smooth solution to be clear from grains and small particles. The liquid extracts have been further diluted with distilled water to obtain 

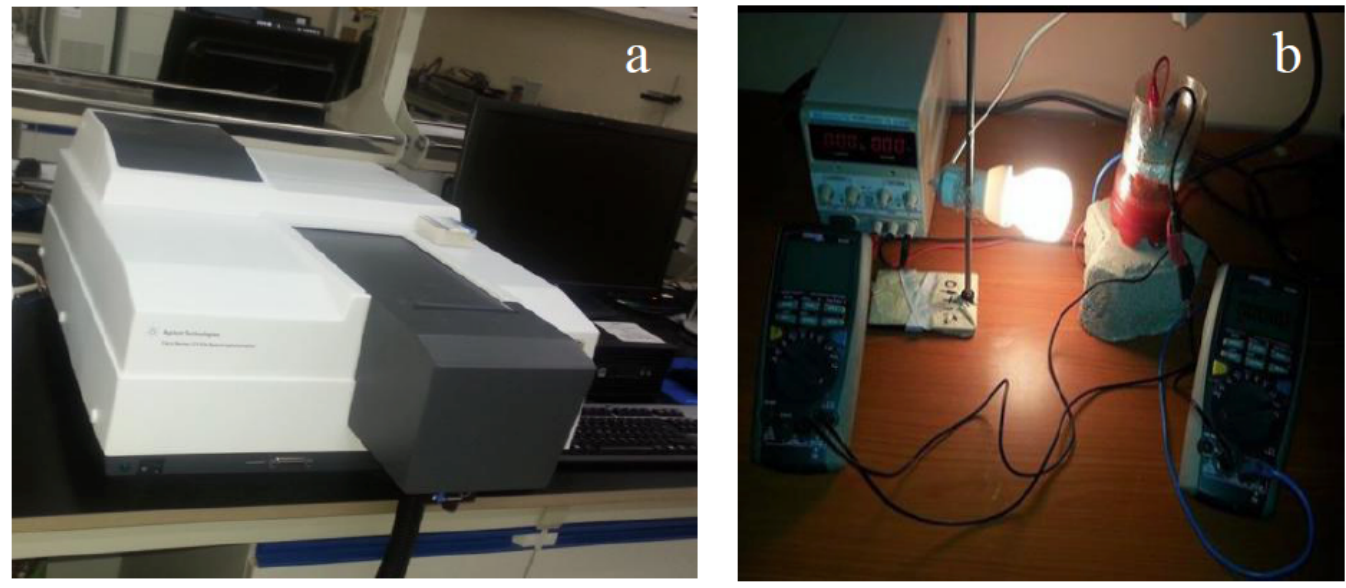

Figure 1: Experimental setup used to record (a) photo-absorption spectra and (b) current-voltage characteristic of the solution samples.

concentrations that does not produce saturated absorption curve in the absorbance spectra. To investigate the photo-absorption, Lambda 25 spectrophotometer (Figure 1a) has been utilized and the optical absorption spectra of the solution samples were recorded in the wavelength range from 200 to 800 $\mathrm{nm}$. The current-voltage investigation under dark and light conditions was recorded by means of digital multimeters. This is where the solution samples have been dropped into specific transparent plastic bottles, and two aluminum electrodes, with $1 \mathrm{~cm}$ apart, were inserted into the solution as shown in Figure $\mathbf{1 b}$. The current-voltage measurement was recorded in the range of $\pm 4.4 \mathrm{~V}$, while a light source with intensity of $11.4 \mu \mathrm{W} / \mathrm{cm}^{2}$ was used for the illumination purpose. The distance between the light source and the solution samples was set to be about $10 \mathrm{~cm}$, while the light was directed perpendicular to the area located between the two electrodes that was filled by the solution samples. All the records were carried out in ambient and under the room temperature of $23{ }^{\circ} \mathrm{C}$. Figure 1 shows the experimental setup used for the investigation of the solution samples.

\section{RESULTS AND DISCUSSION}

Figure 2 shows the absorption spectra of the black grape solution from the ultraviolet (UV) to the visible (Vis) wavelength range. It is seen that the absorption curve has covered a wide range of absorption, extending to about $600 \mathrm{~nm}$. This can be understood as the energy of ultraviolet radiation is readily absorbed by the solution sample to excite electrons from the ground state to the excited state. However, upon decrement of radiation energy i.e. increasing the wavelength, there will be a less probability to excite electrons from the low energy level (ground state) to the higher energy levels (excited states). A relatively abroad absorption peak was noticed at about $550 \mathrm{~nm}$. This was ascribed to the presence of $\pi \rightarrow \pi^{*}$ electronic transitions [18], which is governed by carotenoid and chlorophyll compounds in the black grape juice [19]. Noteworthy, the oscillating absorption behavior in the UV region may refer to the scattering phenomena, which is more likely to occur in the liquids exposed to the high energy radiation.

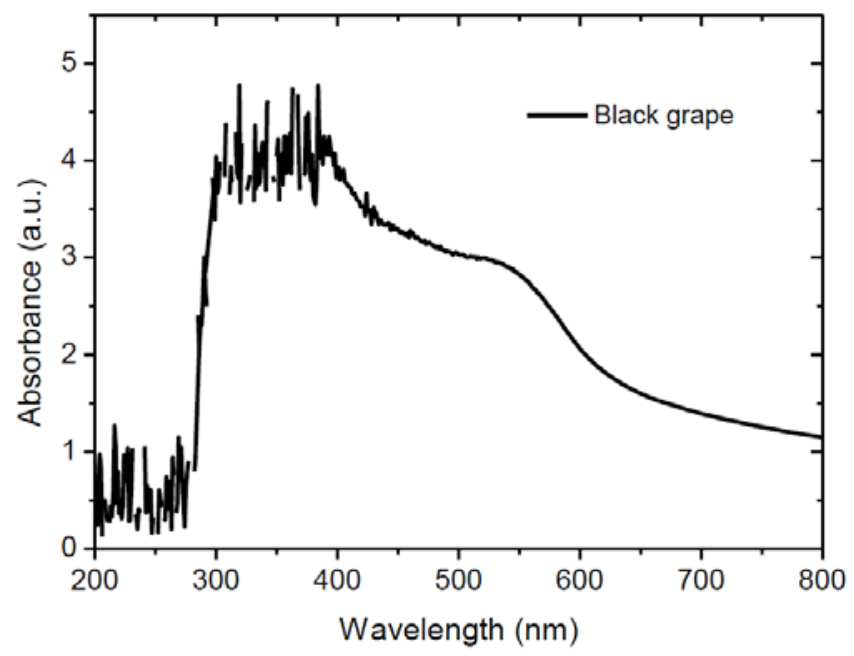

Figure 2: The absorbance spectra of black grape solution.

Figure 3 shows the dark and light current-voltage characteristics of black grape solution in the forward and reverse biased connection. It was noticed that the I- $V$ characteristics showed a non-linear rectification behavior. The rectification ratio, which is defined as the ratio of forward biased current to the reverse biased current, can be calculated using the following equation [20]:

$$
R R=\frac{I_{F}}{I_{R}}
$$


Where, $I_{F}$ and $R_{F}$ are forward biased and reverse biased currents at a specific voltage, respectively. It was found that the rectification ratio at $V= \pm 2.8 \mathrm{~V}$ (at the voltage beyond the potential barrier; potential barrier voltage is obtained by the extrapolating linear part of $\mathrm{I}-V$, where the $\mathrm{x}$-axis intersection represents the barrier value) is almost equal to 0.55 and 1.62 for the dark and light conditions. The higher $R R$ under light compared to that of under dark indicating the occurrence of photovoltaic effect. This is resulted from the interaction of light with the solution molecules to produce photocurrent [20]. It is worth mentioning that the potential barrier $\left(V_{b}=2.0 \mathrm{~V}\right)$ under light was smaller than that of under dark $\left(V_{b}=3.1 \mathrm{~V}\right)$ in the forward biased condition, which is another evidence for the presence of photovoltaic effect in the black grape solution.

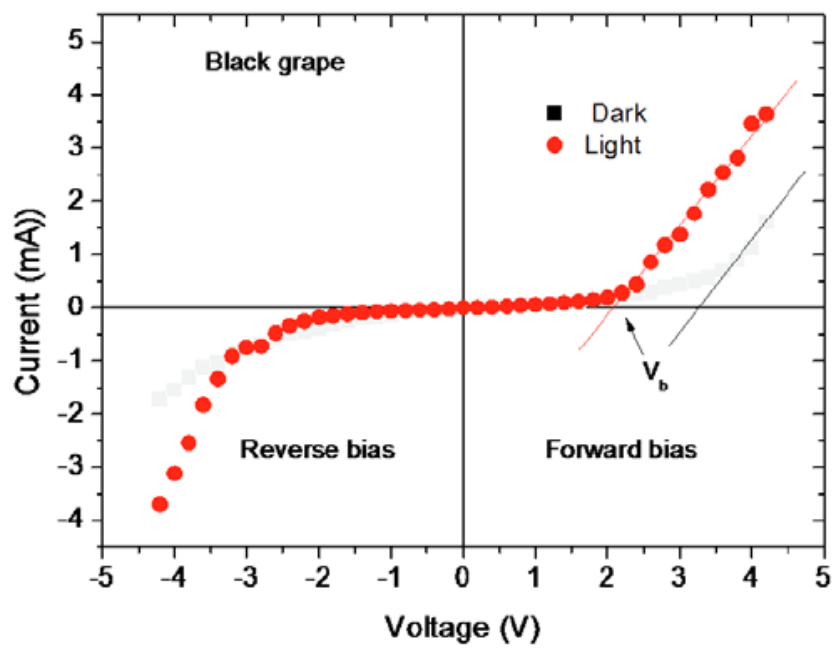

Figure 3: The $I-V$ characteristic of black grape solution in the dark and light condition.

Figure 4 shows the absorption spectra of strawberry solution in the wavelength range from 200 to $800 \mathrm{~nm}$. One can notice the presence of an intense peak at about $500 \mathrm{~nm}$, which is at higher energy level compared to that of black grape at $550 \mathrm{~nm}$. The occurrence of this absorption peak is referred to the presence of electronic transitions from bonding to antibonding molecular orbitals i.e. $\pi \rightarrow \pi^{*}$ electronic transitions. Noticeably, there is a shoulder absorption peak at about $420 \mathrm{~nm}$ for the strawberry solution, which can be attributed to the presence of intermolecular electronics transitions within the sub-energy levels. The differences in absorption energy peak between that of strawberry and that of black grape may refer to the various chlorophyll compounds existed in their juices $[19,21,22]$.

Figure $\mathbf{5}$ shows the current-voltage characteristics of strawberry solution in the voltage range from $4 \mathrm{~V}$ to -

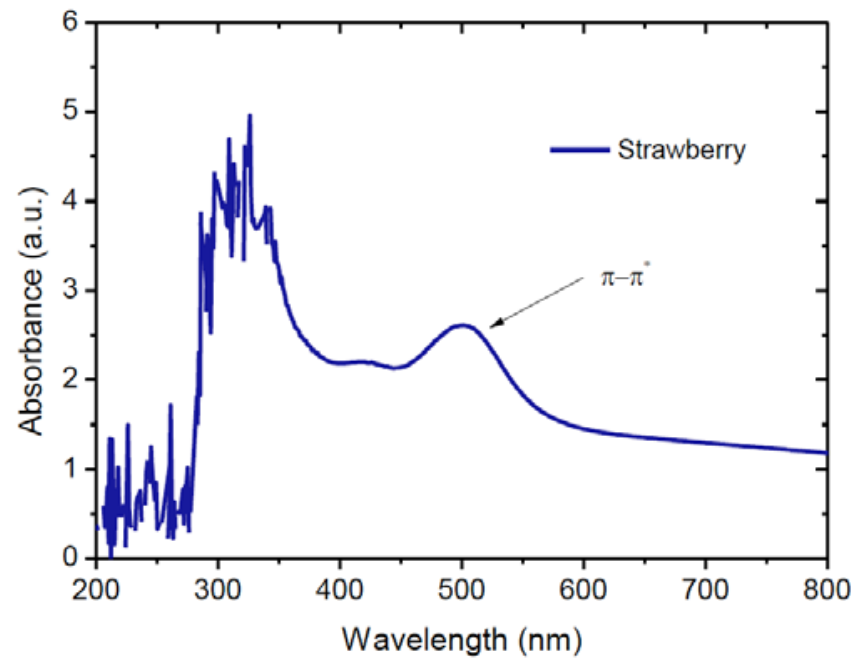

Figure 4: The absorbance spectra of strawberry solution.

4.2 $\mathrm{V}$ under light and dark. In the forward bias, the variation of potential barrier for the strawberry solution upon illumination, to be about $1.1 \mathrm{~V}$, is almost the same as achieved in black grape solution. This property approved that the effect of light incident on the solution is to generate photocurrent, thereby increasing the current passing through the solution. Noticeably, in the reverse biased connection, the photo-current was decreased, meaning that the value of reverse potential barrier has been increased compared to that of the dark condition. This may be ascribed to the hysteric effect generating by the accumulated space charges, which in turn renders the flow of current in reverse direction.

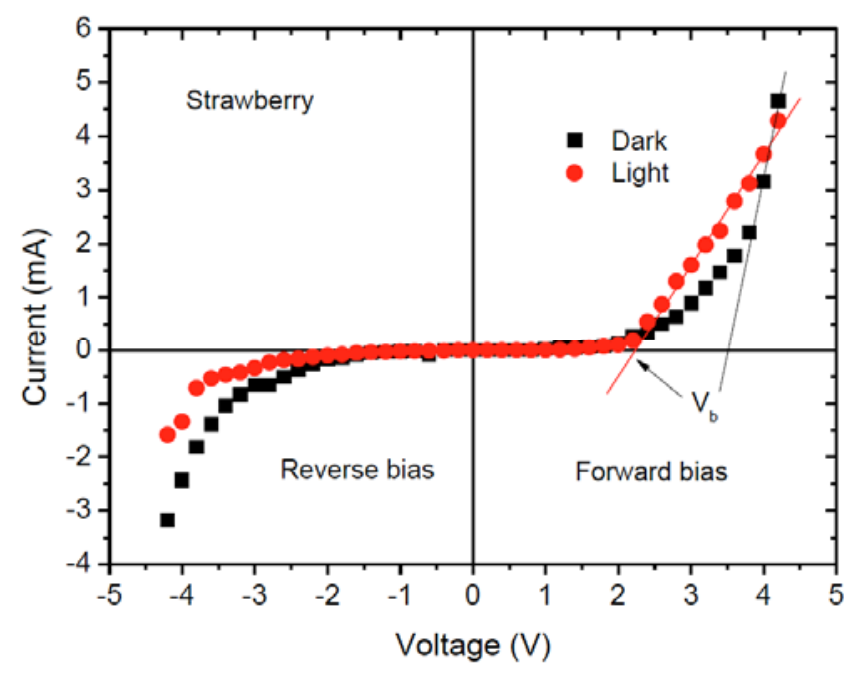

Figure 5: The $I-V$ characteristic of strawberry solution in the dark and light condition.

Figure 6 shows the absorption spectra of the orange solution in the wavelength range from ultraviolet to visible spectrum. The rapid decrease in the absorbance 
from about $360 \mathrm{~nm}$ onward can be correlated to the orange color due to its carotenoid contents [23]. It was seen that the main absorption behavior appeared in the ultraviolet region, which reveals the high transparency of orange juice for the longer wavelengths of visible light spectrum. The absorption process is basically induced by the presence of electrons excitation from the valence band to the conduction band by means of high energy ultraviolet radiation. Worthwhile, the photocurrent activity of the orange solution, as noticed through the curve deviation of under light from that of under dark beyond the potential barrier, was weaker than those of black grape and strawberry solutions (see Figure 7). This is because of that the absorption response in the orange solution is mainly limited within the ultraviolet region of light, while the black grape and strawberry solutions are good absorbers of ultraviolet and visible light energies.

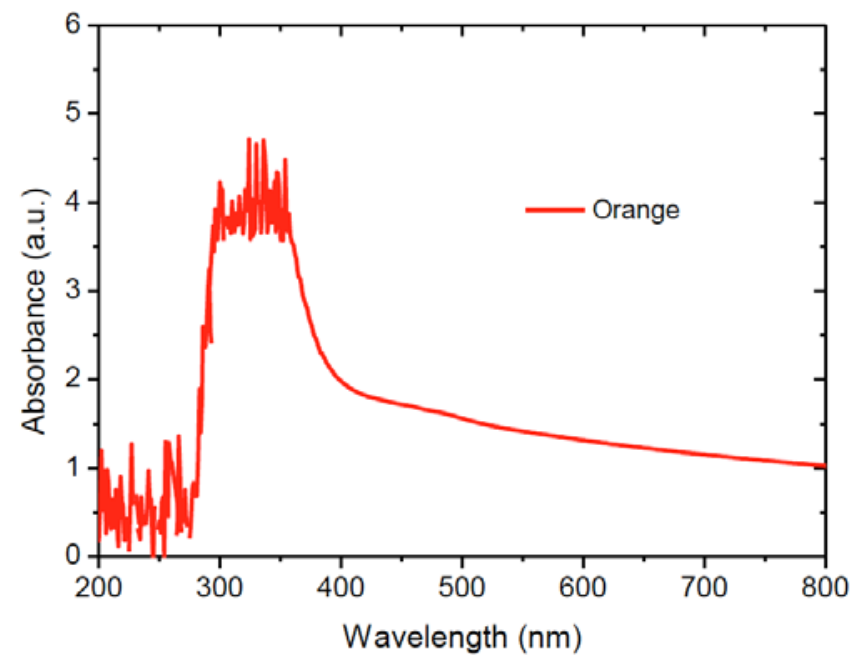

Figure 6: The absorbance spectra of orange solution.

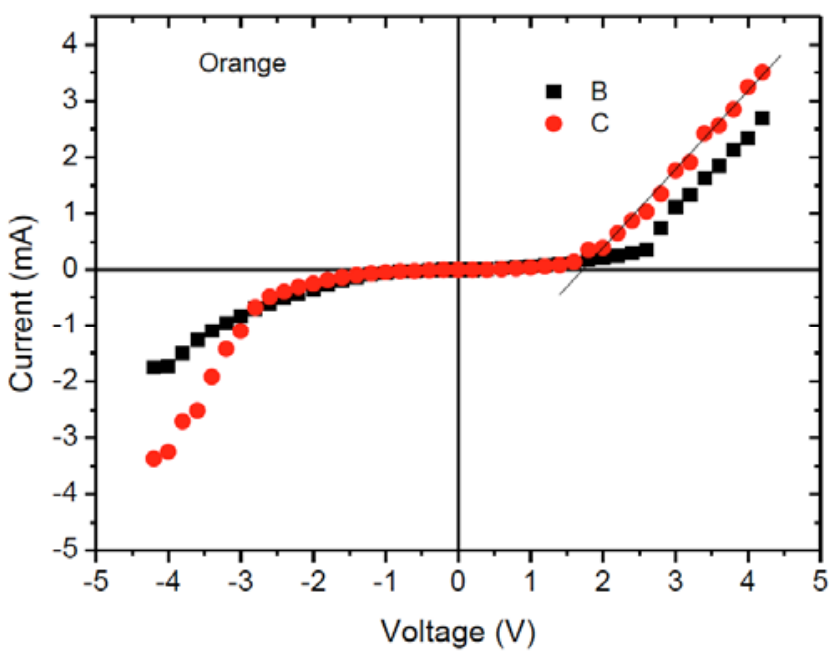

Figure 7: The I-V characteristic of orange solution in the dark and light condition.
Figure 8 shows the comparison of absorption spectra for black grape, strawberry, and orange solutions in the wavelength range from 200 to $800 \mathrm{~nm}$. It was obvious from the figure that black grape showed broader absorption spectra in comparison to those of strawberry and orange solutions. However, upon the comparison of strawberry absorption to those of black grape and orange solutions, two absorption peaks for the strawberry solution was detected. This can be ascribed to the presence of sub-transitional energy bands in the molecules of strawberry. It is worthy to mention that there is a red-shifting absorption in the black grape juice compared to those of strawberry and orange juices. This can be referred to the carotenoid and chlorophyll compounds in the black grape solution, thereby absorbing lower energies spectrum [19].

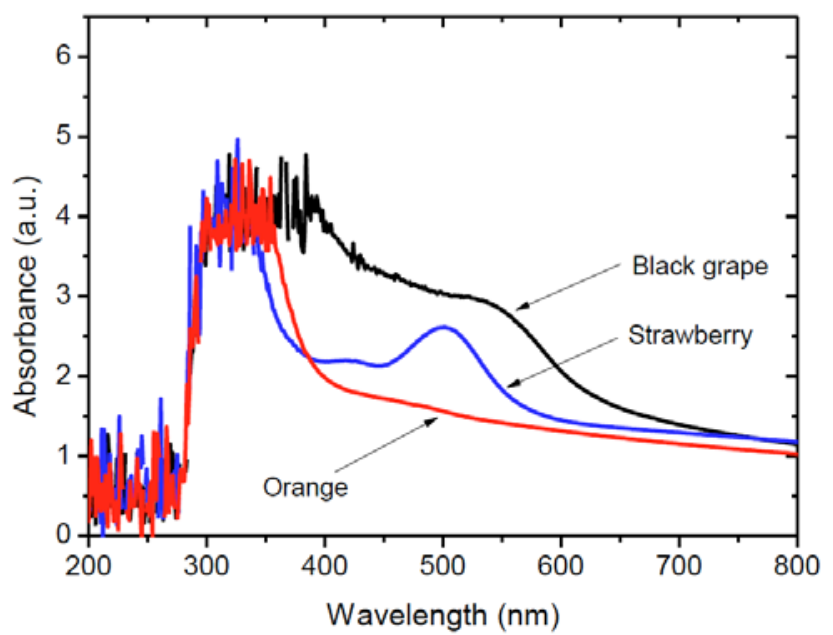

Figure 8: Comparison of the absorption spectra for the fruit solutions under investigation.

Figures 9a-c show the absorption edge region for the black grape, strawberry and orange solutions, respectively, from which the energy gap (the difference between valence and conduction band) can be estimated. The data points regions, where the absorption spectra are decreased rapidly with the increase of wavelength can be utilized to determine energy gap $\left(E_{g}\right)$. This is readily done by extrapolating a straight line to intersect the $x$-axis. The point of intersection gives the $E_{g}$. For the black grape solution, the wavelength $(\lambda)$ of intersection was found to be $675 \mathrm{~nm}$, which is equivalent to the energy gap of $1.84 \mathrm{eV}$. This calculation of $E_{g}$ was performed as follows:

$E=\mathrm{hv}=\mathrm{hc} / \lambda$, where $E$ is the energy of photon, $\mathrm{h}$ is the Planck's constant its value is $6.626 \times 10-34 \mathrm{~J} . \mathrm{s}$, and $\mathrm{C}$ is the velocity of light $\left(3 \times 10^{8} \mathrm{~m} / \mathrm{s}\right), v$ is the frequency of radiation in $\mathrm{Hz}$ or s $\mathrm{s}^{-1}$. Hence; 

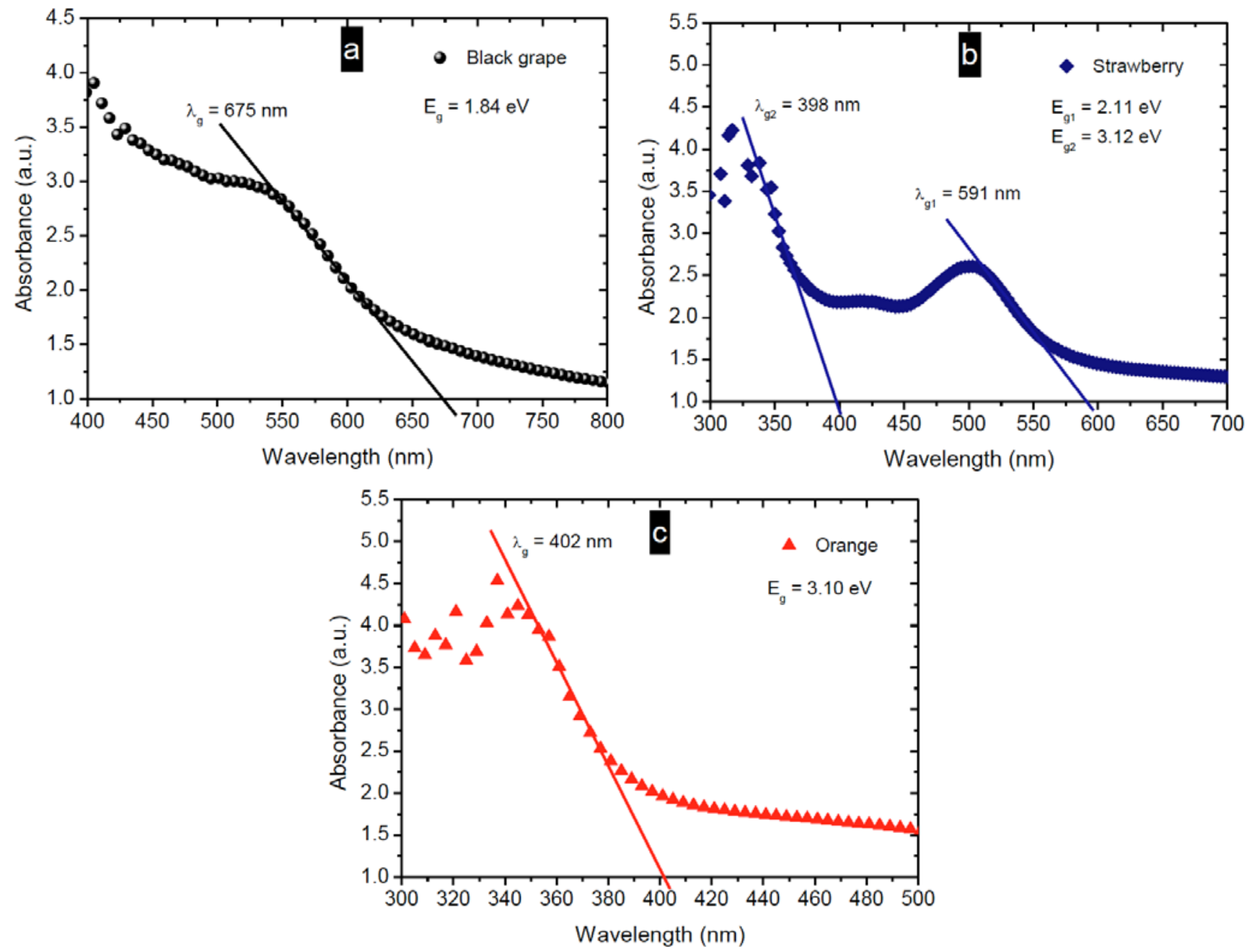

Figure 9: Energy gap estimation for the fruit solutions under investigation.

$E_{g}=\left(4.136 \times 10^{-15} \times 3 \times 10^{8}\right) /\left(675 \times 10^{-9}\right)=1.84 \mathrm{eV}$

Similar calculation procedures were performed for the strawberry and orange samples, as shown in Figures $9 \mathrm{~b}$ and $\mathbf{9 c}$. For the strawberry solution, there were two straight regions of interest. The region of high energy gap $\left(E_{g 1}\right)$ and low energy gap $\left(E_{g 2}\right)$. Hence, the wavelengths $(\lambda)$ of intersection were found to be 398 $\mathrm{nm}$ and $591 \mathrm{~nm}$, respectively. These were equivalent to the energy gap of $3.12 \mathrm{eV}$ and $2.11 \mathrm{eV}$, respectively. Nevertheless, for the orange solution, the absorption edge was found to be $402 \mathrm{~nm}$, which is equivalent to the energy gap of $3.10 \mathrm{eV}$.

Table 1 shows the calculated absorption edge ( $\left.\lambda_{\text {edge}}\right)$ and energy gap for the solution samples. It was seen that the black grape shows smaller energy gap of $1.84 \mathrm{eV}$ compared to those of the strawberry and orange solutions with $2.11 \mathrm{eV}$ and $3.10 \mathrm{eV}$, respectively. As such, the back grape possessed a higher absorption edge in comparison to those of strawberry and orange solutions. This was ultimately resulted in a broader absorption spectrum for the black grape. Worthwhile, the absorption properties of black grape and strawberry juices have been well behaved in the ultraviolet and visible regions, making them a strong candidate for the organic and/or dyes solar cells.

Table 1: The Absorption Edge and Energy Gap of Solution Samples

\begin{tabular}{|c|c|c|}
\hline Solution Sample & $\begin{array}{c}\text { Absorption Edge, } \\
\lambda_{\text {edge }}(\mathbf{n m})\end{array}$ & $\begin{array}{c}\text { Energy Gap, } \\
\boldsymbol{E}_{g}(\mathrm{eV})\end{array}$ \\
\hline \hline Black grape & 675 & 1.84 \\
\hline Strawberry & 591 & 2.11 \\
\hline Orange & 402 & 3.10 \\
\hline
\end{tabular}

\section{CONCLUSIONS}

Solutions of the black grape, strawberry and orange were extracted from fruits in fresh form and their photoabsorption and photovoltaic properties were 
successfully investigated, aiming at verifying their potential application for organic/dye solar cells. The results showed that the energy gap of the fruits were very well located within the visible light spectrum. The energy gap of the juices was determined to be $1.84 \mathrm{eV}$ for black grape, $2.11 \mathrm{eV}$ for strawberry and $3.10 \mathrm{eVfor}$ the orange. Besides, the results of black grape and strawberry solutions showed broad absorption spectra covering almost all the part of the visible light, indicating their viability to harvest solar energy. Nevertheless, the absorption of black grape showed a broader spectrum compared to those of other fruits. Moreover, the results of photovoltaic investigations for the fruit samples showed a considerable increase in the photocurrent generation as a result of illumination process. The black grape solution showed enhanced photo-current activity compared to those of other solutions, reflecting the broad photo-absorption response in the black grape sample. It was concluded that fruit extracts can be a viable candidate to be utilized in the fabrication of nanostructured organic and/or dyes solar cells.

\section{ACKNOWLEDGEMENT}

The authors are thankful to the Department of Chemistry, Koya University, for facilitating the cuvette and filtration paper used in the study. We should also thank Dr. Shujahadeen B. Aziz at the Department of Physics, University of Suaimani for his helps in recording the absorption spectra for the samples.

\section{CONFLICT OF INTERESTS}

The authors declare that there is no conflict of interests regarding the publication of this article.

\section{REFERENCES}

[1] Muhammad FF, Sulaiman K. Photovoltaic performance of organic solar cells based on DH6T/PCBM thin film active layers. Thin Solid Films 2011; 519: 5230-3. http://dx.doi.org/10.1016/i.tsf.2011.01.165

[2] Muhammad FF. Design approaches to improve organic solar cells. Journal of Technology Innovations in Renewable Energy 2014; 3: 1-8. http://dx.doi.org/10.6000/1929-6002.2014.03.02.4

[3] Bartolotta A, Calogero G, Crupi C, Marco GD. RTV silicone membranes as agents to confine the liquid components in dye sensitized solar cells. J Mater 2013; 2013: 1-10. http://dx.doi.org/10.1155/2013/597616

[4] Sudhahar S, Kumar MK, Silambarasan A, Muralidharan R, Kumar RM. Studies on Structural, Spectral, and Optical Properties of Organic Nonlinear Optical Single Crystal: 2Amino-4,6-dimethylpyrimidinium p-Hydroxybenzoate. J Mater 2013; 2013: 1-8.

http://dx.doi.org/10.1155/2013/539312
[5]

Muhammad FF, Abdul Hapip Al, Sulaiman K. Study of optoelectronic energy bands and molecular energy levels of tris (8-hydroxyquinolinate) gallium and aluminum organometallic materials from their spectroscopic and electrochemical analysis. J Organometal Chem 2010; 695: 2526-31.

http://dx.doi.org/10.1016/j.jorganchem.2010.07.026

[6] Muhammad FF, Sulaiman K. Tuning the Optical Band Gap of DH6T by Alq3 Dopant. Sains Malaysiana 2011; 40: 17-20.

[7] Duran L, Calvo C. Optical properties of foods. Food Eng 2003; 1: 1-9.

[8] Saeys W, Velazco-Roa MA, Thennadil SN, Ramon H, Nicolaï BM. Optical properties of apple skin and flesh in the wavelength range from 350 to $2200 \mathrm{~nm}$. Appl Opt 2008; 47: 908-19. http://dx.doi.org/10.1364/AO.47.000908

[9] Qin J, Lu R. Measurement of the optical properties of fruits and vegetables using spatially resolved hyperspectral diffuse reflectance imaging technique. Postharvest Biol Technol 2008; 49: 355-65.

http://dx.doi.org/10.1016/i.postharvbio.2008.03.010

[10] Wanitchang $\mathrm{P}$, Terdwongworakul A, Wanitchang J, Nakawajana N. Non-destructive maturity classification of mango based on physical, mechanical and optical properties. J Food Eng 2011; 105: 477-84.

http://dx.doi.org/10.1016/i.jfoodeng.2011.03.006

[11] Nassif R, Pellen F, Magné C, Le Jeune B, Le Brun G, Abboud M. Scattering through fruits during ripening: laser speckle technique correlated to biochemical and fluorescence measurements. Opt Express 2012; 20: 2388797. http://dx.doi.org/10.1364/OE.20.023887

[12] Pilarski J, Tokarz K, Kocurek M. Optical Properties of the Cork of Stems and Trunks of Beech (Fagus Sylvatica L.). Polish J of Environ Stud 2008; 17: 773-9.

[13] Slaughter DC. Nondestructive internal quality assessment of kiwifruit using near-infrared spectroscopy. Sem Food Anal 1998; 3: 131-40.

[14] Baranyai L, Regen C, Zude M. Monitoring optical properties of apple tissue during cool storage. Workshop on Image Analyses 2009; ISSN 0947-7314: 112-9.

[15] Qin J, Lu R. Measurement of the absorption and scattering properties of turbid liquid foods using hyperspectral imaging. Appl Spectrosc 2007; 61: 388-96. http://dx.doi.org/10.1366/000370207780466190

[16] Gomez-Ortiz N, Vázquez-Maldonado I, Pérez-Espadas A Mena-Rejón G, Azamar-Barrios J, Oskam G. Dye-sensitized solar cells with natural dyes extracted from achiote seeds. Solar Energy Mater Solar Cells 2010; 94: 40-4. http://dx.doi.org/10.1016/j.solmat.2009.05.013

[17] Hao S, Wu J, Huang Y, Lin J. Natural dyes as photosensitizers for dye-sensitized solar cell. Solar Energy 2006; 80: 209-14.

http://dx.doi.org/10.1016/j.solener.2005.05.009

[18] Muhammad FF, Sulaiman K. Utilizing a simple and reliable method to investigate the optical functions of small molecula organic films - Alq3 and Gaq3 as examples. Measurement 2011; 44: 1468-74 http://dx.doi.org/10.1016/j.measurement.2011.05.017

[19] Mendes-Pinto MM, Silva Ferreira AC, Caris-Veyrat C Guedes de Pinho P. Carotenoid, chlorophyll, and chlorophyllderived compounds in grapes and port wines. J Agr Food Chem 2005; 53: 10034-41. http://dx.doi.org/10.1021//f0503513

[20] Saleem M, Sayyad MH, Karimov KS. Electrical characteristics of solid-liquid rectifying junctions. Arab J Sci Eng 2014; 39: 541-5.

http://dx.doi.org/10.1007/s13369-013-0860-2 
[21] Razavi F, Pollet B, Steppe K, Labeke MC. Chlorophyll fluorescence as a tool for evaluation of drought stress in strawberry. Photosynthetica 2008; 46: 631-3. http://dx.doi.org/10.1007/s11099-008-0108-7

[22] Valkama E, Kivimäenpää $M$, Hartikainen $H$, Wulff $A$. The combined effects of enhanced UV-B radiation and selenium on growth, chlorophyll fluorescence and ultrastructure in strawberry (Fragaria $x$ ananassa) and barley (Hordeum vulgare) treated in the field. Agricultural and Forest Meteorology 2003; 120: 267-78.

http://dx.doi.org/10.1016/j.agrformet.2003.08.021

[23] Meléndez-Martínez AJ, Gómez-Robledo L, Melgosa M, Vicario IM, Heredia FJ. Color of orange juices in relation to their carotenoid contents as assessed from different spectroscopic data. Journal of Food Composition and Analysis 2011 ; 24: 837-44.

http://dx.doi.org/10.1016/.j.jca.2011.05.001 